\title{
CaCoCur
}

\section{un portal web para la difusión de contenidos multimedia culturales de las universidades públicas andaluzas}

\author{
Por José-L. Bernier, David Gómez-Domínguez, Gerardo Fernández-Rodríguez, Mario-J. Barchéin y \\ Gregorio Pérez
}

\begin{abstract}
Resumen: La Asociación de Universidades Públicas Andaluzas (AUPA) ha presentado un portal que ofrece contenidos multimedia relacionados con los actos culturales organizados por dichas instituciones, con objeto de difundir este rico patrimonio cultural a través de internet. Este portal, denominado $\mathrm{CaCoCu}$, permite el acceso a material audiovisual tal como grabaciones de vídeo y audio, documentos de texto o galerías de imágenes que versa sobre temáticas muy variadas. En este artículo se describe su arquitectura tanto en el aspecto tecnológico como en el documental, así como las funcionalidades y servicios que se prestan a través del mismo.
\end{abstract}

Palabras clave: Portales web, Web 2.0, Patrimonio cultural, Universidades andaluzas, Difusión de vídeo.

Title: CaCoCur a website for the dissemination of cultural multimedia content from public universities in AndaIusia.

Abstract: The Association of Public Andalusian Universities (AUPA) has introduced a portal that offers diverse multimedia content related to cultural events organised by these institutions, and whose objective is to disseminate this rich cultural heritage over the internet. The website, named CaCoCu, allows users to access audio-visual materials such as audio or video recordings, text documents and image galleries related to different themes. This paper describes the architecture of the web portal, taking into account both technological and documentary aspects, as well as the functionality and services that are provided.

Keywords: Web portals, Web 2.0, Cultural heritage, Andalusian universities, Video broadcasting.

Bernier, José-L.; Gómez-Domínguez, David; Fernández-Rodríguez, Gerardo; Barchéin, Mario-J.; Pérez, Gregorio. "CaCoCu: un portal web para la difusión de contenidos multimedia culturales de las universidades públicas andaluzas". En: El profesional de la información, 2007, mayo-junio, v. 16, n. 3, pp. 216-224.

DOI: 10.3145/epi.2007.may.06

\section{Introducción}

HOY DÍA LAS HERRAMIENTAS DE DISEÑO Y PROGRAMACIÓN WEB permiten diseñar aplicaciones y servicios remotos de gran calidad con prestaciones similares a las que ofrece una aplicación convencional de escritorio.
Además, el tiempo de respuesta es comparable gracias a que el ancho de banda usado en las comunicaciones ha crecido y no constituye una restricción en muchos casos. 


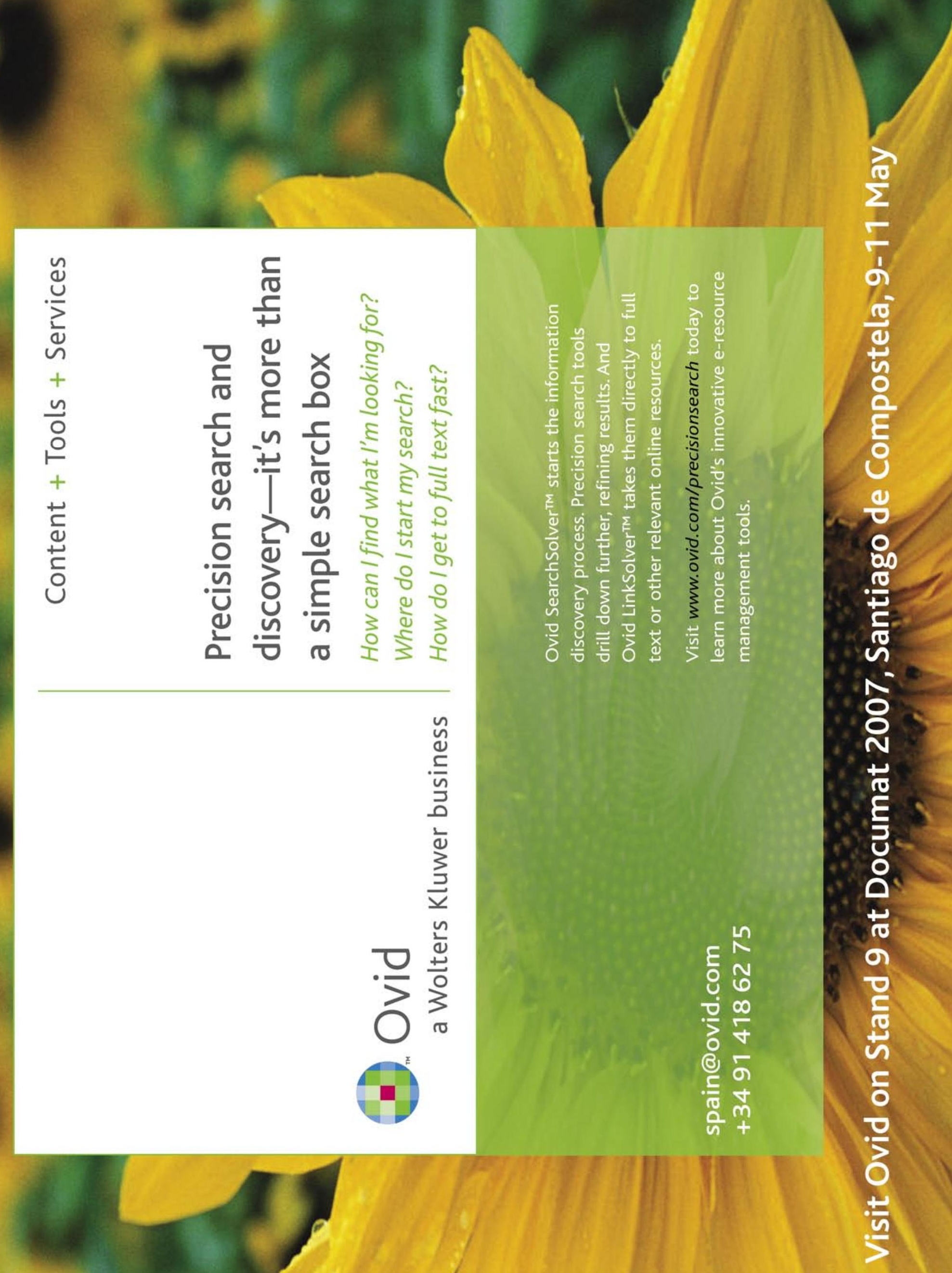




\section{"CaCoCu ofrece materiales audiovisuales culturales sobre las actividades organizadas por las universidades públicas de Andalucía"}

De esta forma, el navegador puede considerarse ahora como una consola donde ejecutar programas, más que una simple pasarela para visualizar páginas web.

Disponer de aplicaciones o servicios web ofrece ventajas como:

- No ocupan espacio de almacenamiento, ya que no deben instalarse en el ordenador cliente.

- Los usuarios acceden siempre a la versión más reciente del programa.

- No afecta el sistema operativo que tenga instalado el cliente, ni otras restricciones relacionadas con la plataforma hardware que use.

Este nuevo paradigma se ha bautizado como web $2.0^{1}$ y está modificando la filosofía de internet. En esta línea, Google está trabajando en su paquete de oficina con funcionalidad análoga a la que ofrece Microsoft Office pero, a diferencia de éste, se ejecuta desde el navegador a través de la $\operatorname{Red}^{2}$.

Web 2.0 no sólo se refiere al diseño de servicios web y aplicaciones remotas, sino que persigue también enriquecer los contenidos con las aportaciones de los navegantes, con lo que éstos pasan de ser simples espectadores a colaborar activamente, haciéndoles sentir partícipes del éxito del portal. Tal es el caso de los wikis o de los blogs, que consiguen difundir conocimiento a partir de múltiples aportaciones individuales.

Otra de las tendencias actuales es la difusión de vídeo ${ }^{3}$, pues el ancho de banda habitual ya permite su transmisión, algo que parecía inabordable poco tiempo atrás ${ }^{4}$. Así, recientemente se ha popularizado
YouTube, un portal web 2.0 cuyo éxito provocó que Google lo adquiriera en octubre de 2006 por 1.650 millones de US\$.

Este artículo se encuadra dentro de las líneas de actuación anteriormente citadas. Se describe un portal web denominado Canal de Cultura Contemporánea $(\mathrm{CaCoCu})$ que ofrece materiales audiovisuales (grabaciones de vídeo, audio, textos o imágenes) de las actividades culturales organizadas por las universidades públicas de Andalucía, que se han asociado en la $A U P A$ (Asociación de Universidades Públicas de Andalucía) $)^{5}$. A través de la misma los Vicerrectorados de Extensión Universitaria de los centros participantes colaboran en un proyecto denominado Atalaya, que pretende aumentar la difusión de exposiciones, teatro, conciertos, conferencias, etc.

\section{http://www.cacocu.es}

\section{Arquitectura del portal}

Se sustenta sobre xhtml y css $^{6}$ como tecnología de diseño web, php5 $5^{7}$ en cuanto al lenguaje de programación y $\mathrm{MySQL}^{8}$ como motor de bases de datos; se usa Apache ${ }^{9}$ como servidor web y Windows media server ${ }^{10}$ como servidor de stream, instalados sobre máquinas distintas.

En la planificación y puesta en marcha del portal han intervenido diversos especialistas:

- Un diseñador gráfico encargado de configurar el aspecto de las distintas páginas, la elaboración de logos y presentaciones, etc.

- Un programador web para implementar scripts y servicios, así como codificar el diseño en $\mathrm{xhtml}+\mathrm{css}$.

- Un documentalista responsable de la ficha descriptiva y del sistema de clasificación de los materiales, así como de la alimentación y mantenimiento de la plataforma.

- Un técnico multimedia que convierte los recursos a formatos adecuados para su difusión por internet.

- Un analista coordinador del trabajo conjunto de este equipo.

El portal ha sido realizado a medida en su totalidad, diseñándose un gestor de contenidos para llevar a cabo su administración y mantenimiento a través de webs.

En relación con los usuarios y sus perfiles de acceso se ha considerado la siguiente jerarquía:

- Administrador de la aplicación: tiene acceso a todos los servicios y a su gestión.

- Colaborador: puede añadir contenidos, editar las fichas descriptivas, moderar los comentarios o los foros, etc.

- Usuarios registrados: pueden acceder a servicios exclusivos y personalizados.

- Usuarios no registrados: tienen acceso a los contenidos del portal con algunas restricciones.

\section{Dificultades}

Pueden destacarse dos:

1. Difusión de vídeo.

2. Tratamiento documental de la diversidad de materiales recibidos (ver el apartado 3. Documentación).

La difusión de vídeo a través de internet exige la utilización de formatos de stream. Los sistemas tradicionales de descarga necesitan que se baje el archivo completo antes de poder acceder al mismo. En cambio, el stream de vídeo permite que se pueda visualizar conforme avanza la descarga. Existen distintas tecno- 
logías, pero hay que tener en cuenta que las grabaciones que se proporcionan a través de $\mathrm{CaCoCu}$ tienen, por lo general, una duración superior a 1 hora, con lo que cualquier formato de stream no es eficiente. Por ello fue necesario analizar el formato adecuado, decidiéndose adoptar Windows media video $(w m v)^{10}$ ya que, además de la difusión de grabaciones de larga duración, soporta algunas características interesantes para los objetivos del portal:

- Difusión bajo demanda y en directo.

- Difusión multicast (envío simultáneo de información a un grupo de receptores utilizando la estrategia más eficiente para entregar los mensajes sólo una vez, creando copias sólo cuando las conexiones a los destinos se dividen).

- Cuando se usa bajo demanda se puede adelantar el punto de inicio del vídeo.
- Multiple bit rate $(M B R)$ : en un único archivo se puede codificar el vídeo con distintas calidades $\mathrm{y}$, por tanto, con diferentes requerimientos de ancho de banda. De esta forma el servidor de stream negocia con el cliente la calidad óptima en función del ancho de banda soportado por la red. Es más, durante la visualización el servidor puede modificar dinámicamente la calidad sin interrumpir su difusión, para adaptarse al estado de saturación de la red.

Así pues, las grabaciones se han codificado a distintos bit-rates para que, por un lado, no se limite la calidad y, por otro, no se restrinja el acceso a usuarios con conexiones a internet deficientes. El usuario tiene la posibilidad de elegir entre dos rangos de calidad: uno bajo, cuyo bit-rate oscila entre 96 y $150 \mathrm{Kbps}$, y otro de alta calidad, que lo hace entre 200 y 450 Kbps. En ambos se usa una resolución de 400×300 píxeles, consistiendo la principal diferencia en que a baja calidad se aplica un frame rate de $15 \mathrm{fps}$ y a alta uno de $25 \mathrm{fps}$. Por otra parte, la calidad de audio es también inferior si se escogen rangos inferiores ya que así se baja el bit-rate.

\section{Filosofía web 2.0 del portal}

- Se han seguido los estándares de diseño y accesibilidad, de forma que $\mathrm{CaCoCu}$ se ha implementado usando xhtml+css por un lado, y respetando la normativa $W A I^{11}$ por otro. Xhtml garantiza la correcta visualización de las páginas en cualquier navegador que lo acepte, evitando los inconvenientes de html. Por su parte, WAI es de obligatorio cumplimiento para las instituciones públicas y facilita el acceso a personas con discapacidad visual.

- Se permite la sindicación de contenidos (rss) ${ }^{12}$.

- El acceso a los materiales puede realizarse mediante un nave-

\section{Introduciendo}

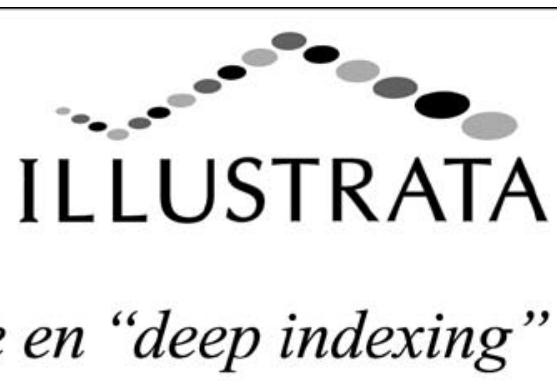

\section{Herramienta que cambia el modo en cómo los investigadores interactúan con el proceso de descubrimiento de información}
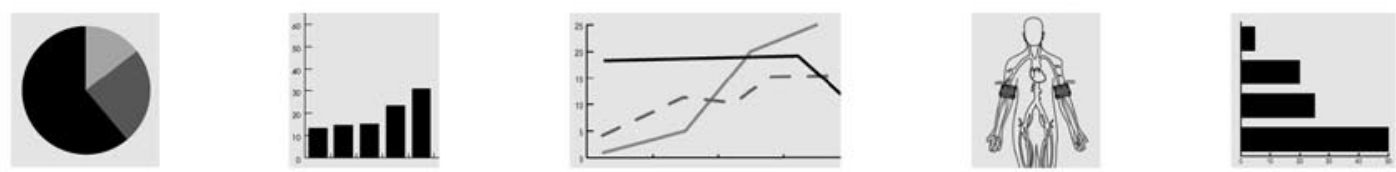

Este nuevo método para localizar información permite a investigadores y bibliotecarios...

- Encontrar material difícil de localizar incluso dentro de artículos académicos

- Ahorrar tiempo con búsquedas más focalizadas

- Hacer fácilmente presentaciones visuales para ponencias de conferencias o para propósitos docentes
Tablas e imágenes y mucho más...

CSA Illustrata reúne una gran variedad de recursos de artículos peer-reviewed:

$\begin{array}{ll}\text { - tablas } & \text { - mapas } \\ \text { - ilustraciones } & \text { - fotografias } \\ \text { - gráficos } & \text { - imágenes } \\ \text { - cuadros } & \end{array}$

Los pies de imagen se incluyen en todos los registros

\section{ProGuest CSA}

4640 Kingsgate

Cascade Way

Oxford Business Park South

Oxford OX4 2SU, UK www.esa.com
Para un acceso de prueba 0 información adicional vaya a: 


\section{Ficha técnica. Entre paréntesis se indica el valor predeterminado:}

- Título.

- Responsables.

- Categoría (nivel 1 taxonomía).

- Tipo de actividad (nivel 2 taxonomía).

- Lugar de celebración.

- Fecha de celebración.

- Organizado por.

- Universidad llas 10 universidades andaluzas).

- Duración del acto recogido en el documento.

- Tipo de medio (vídeo, audio, imagen simple, galería de imágenes, texto y net-art).

- Tamaño en MB.

- Páginas en el caso de que se trate de un documento textual en formato $\mathrm{pdf}$.
- Publicación: lugar: editor, año.

- ISBN.

- Depósito legal.

- En (pertenece a): para cuando se trata de textos que forman parte de alguna publicación colectiva.

- Descripción.

- Materias.

- Url.

- Número total de imágenes que conforma una galería.

- Colección: para materiales que forman parte de la misma serie, como el caso de "Una semana con Saramago", organizada por la Universidad de Granada y de la que se obtiene más de una grabación en DVD.

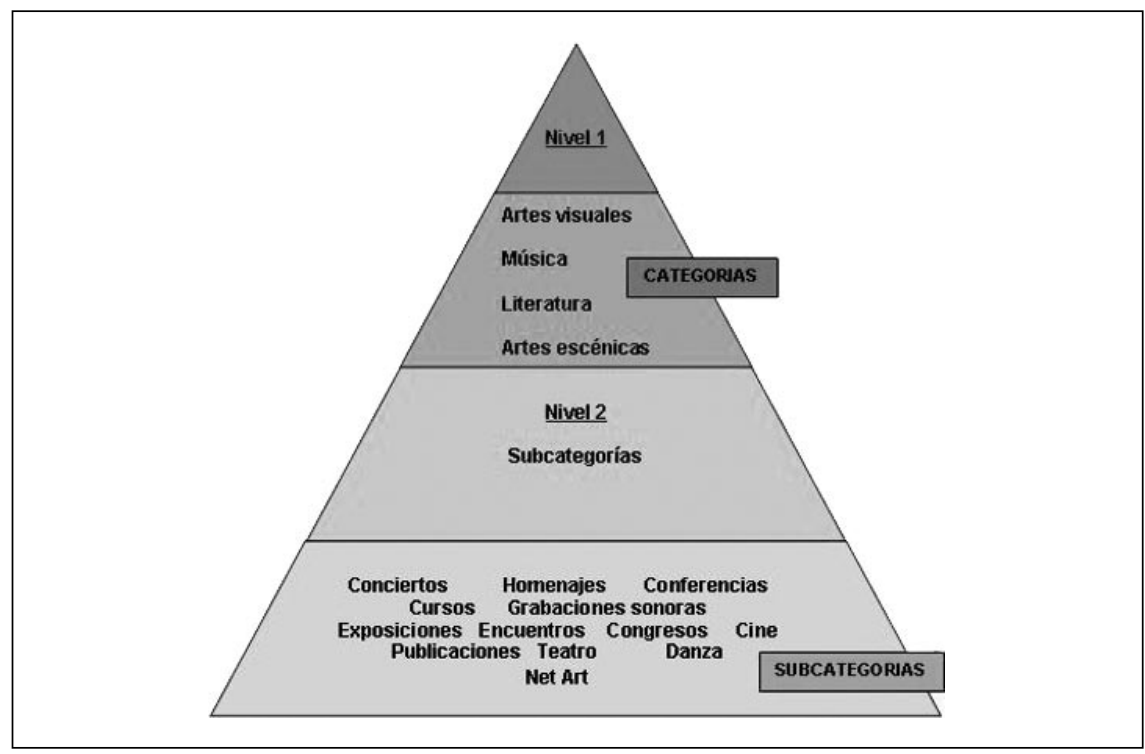

Figura 1. Niveles de la taxonomía del portal
"La arquitectura básica se sustenta sobre $\mathrm{xhtml+css,}$ PHP5 y MySQL. Se usa Apache como servidor web y Windows media server como servidor de stream" gador basado en descriptores. Cada contenido tiene asociado una o más etiquetas de forma que al usuario se le muestran con un tamaño de letra proporcional al número de contenidos que la contienen.

- Se envían alertas a los usuarios que lo desean para avisarles de novedades de su interés.

\section{"Se distribuyen \\ grabaciones de vídeo y de audio, galerías de imágenes y documentos de texto"}

- La jerarquía de usuarios contempla la posibilidad de colaboradores para que las tareas de añadir contenidos y editar descripciones no estén necesariamente centralizadas. Además se abre la posibilidad futura de que los usuarios registrados puedan aportar creaciones artísticas propias, enriqueciendo los contenidos del portal.

- Se ha diseñado para ofrecer soporte multilingüe tanto a nivel de menús como de contenidos.

\section{Documentación}

Tal y como se mencionó en la sección anterior, una de las grandes dificultades encontradas ha sido la heterogeneidad de los materiales a 


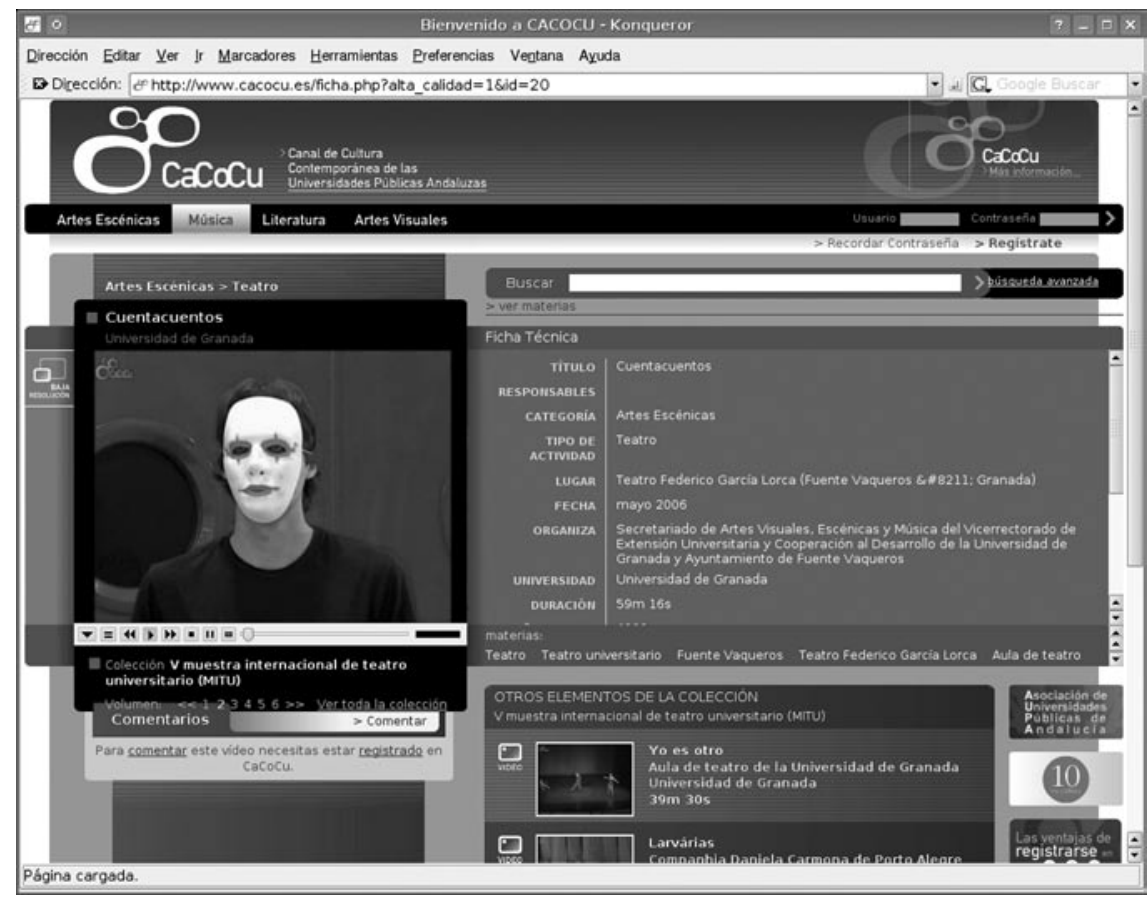

Figura 2. Acceso a los contenidos de vídeo

ofrecer, lo que ha complicado tanto el diseño de su ficha descriptiva y base de datos, como la definición de la taxonomía.

Para facilitar la navegación a los usuarios (fundamentalmente los inexpertos), se decidió crear una clasificación en dos niveles. En la figura 1 se recogen las subcategorías correspondientes a cada uno de los niveles o categorías principales establecidas.

De esta manera cualquier material relacionado con exposiciones de pintura, por ejemplo, se ubicará bajo Artes visuales-Exposiciones.

Algo similar ocurrió con la realización de las fichas descriptivas estándar por tipo de material. La solución fue elaborar una única ficha donde quedaban recogidos todos los campos de descripción con la condición de que sólo fuesen

\section{"Los usuarios localizan los contenidos a través de una taxonomía, por materias, y mediante buscador (simple y avanzado)"}

mostrados aquéllos que quedaran cumplimentados.

Tanto los campos como los niveles y sub-niveles de la taxonomía podrán verse ampliados en el momento que sea necesario por la aparición de nuevos tipos de materiales.

\section{"En el futuro $\mathrm{CaCoCu}$ abordará la difusión de vídeo en directo y la recuperación del patrimonio cultural más antiguo"}

\section{Usabilidad}

Se ofrecen 4 tipos de contenidos:

- Grabaciones de vídeo.

- Archivos de audio.

- Galerías de imágenes.

- Documentos de texto.

Se organizan en colecciones. Por ejemplo, puede haber un ciclo de conferencias sobre una temática particular, de forma que todo lo referente a dicha actividad se agrupa como una colección, permitiéndose también el acceso individual a cada uno de los materiales que la constituyen.

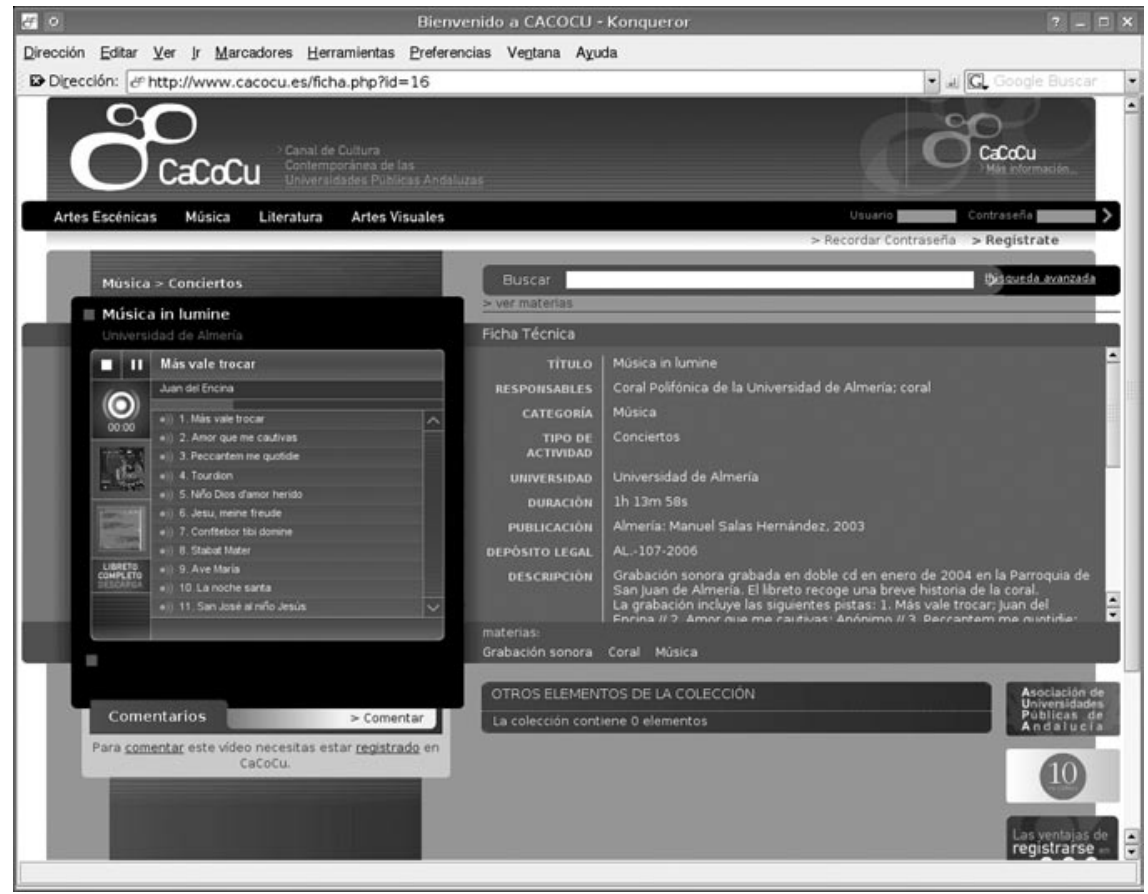

Figura 3. Acceso a los contenidos de audio 
Se utilizan visores incrustados en la propia página web, de forma que no se requieren reproductores externos en ningún caso. El aspecto general de las páginas que visualizan algún medio es similar al mostrado en la figura 2; el contenido se muestra en el visor situado la izquierda y a su lado aparece su ficha.

\section{Reproducción de vídeo}

Gran parte del material accesible son obras de teatro, conferencias, lecturas poéticas, entrevistas, etc., tal y como muestra la figura 2 .

\section{Reproducción de audio}

Grabaciones de conciertos, corales, producciones musicales editadas en estudio, etc. En este caso (figura 3) el visualizador muestra la lista de temas seleccionables. Como opciones se puede mostrar la portada y contraportada del cd en cuestión, o descargar el libreto completo en formato pdf, siendo posible leerlo sin que deje de escucharse la música.

\section{Galerías de imágenes}

Imágenes fijas de exposiciones de pintura, escultura, fotografía, etc. Los controles permiten seleccionar la imagen que se mostrará en el visor y, opcionalmente, puede activarse la visualización en alta resolución. La ficha describe la galería completa pero si se decide ver las imágenes en alta resolución se lee una descripción de cada una de ellas.

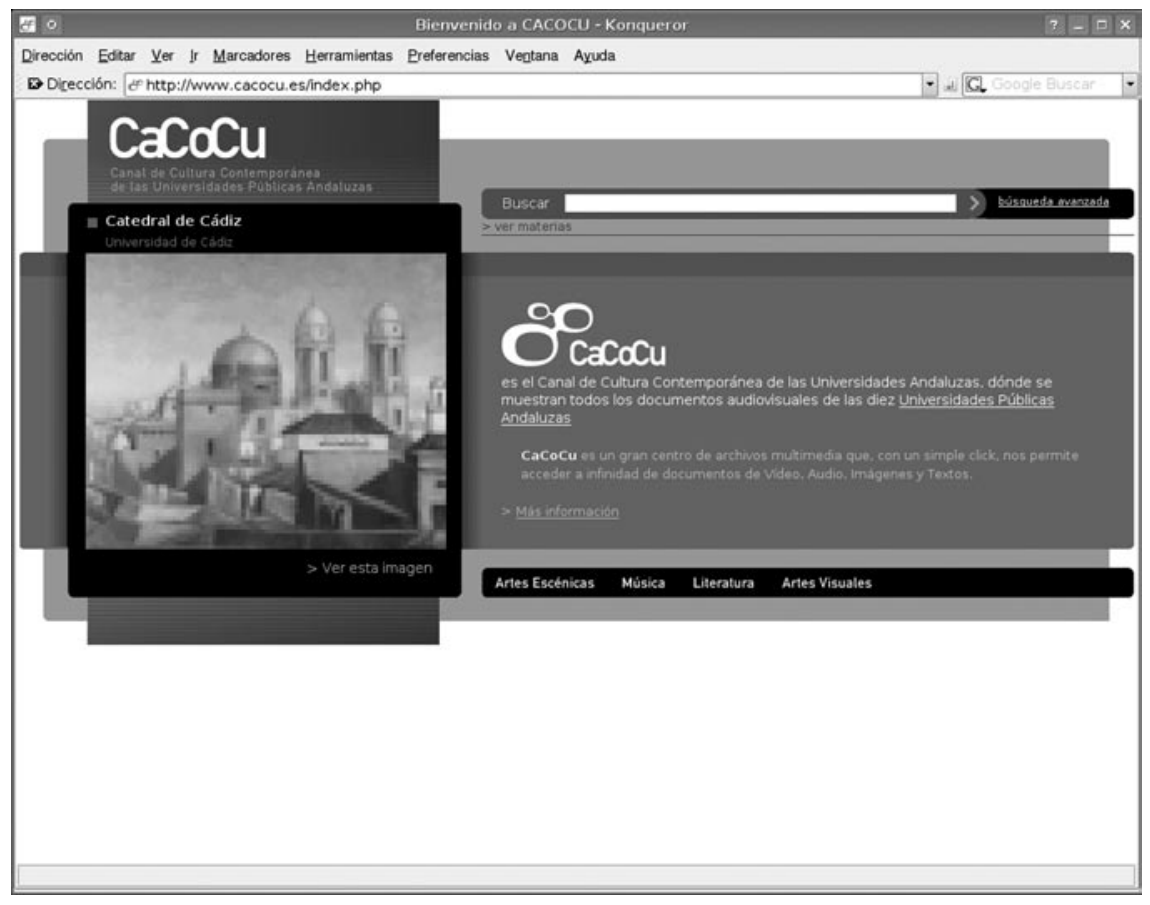

Figura 4. Acceso a los contenidos del portal

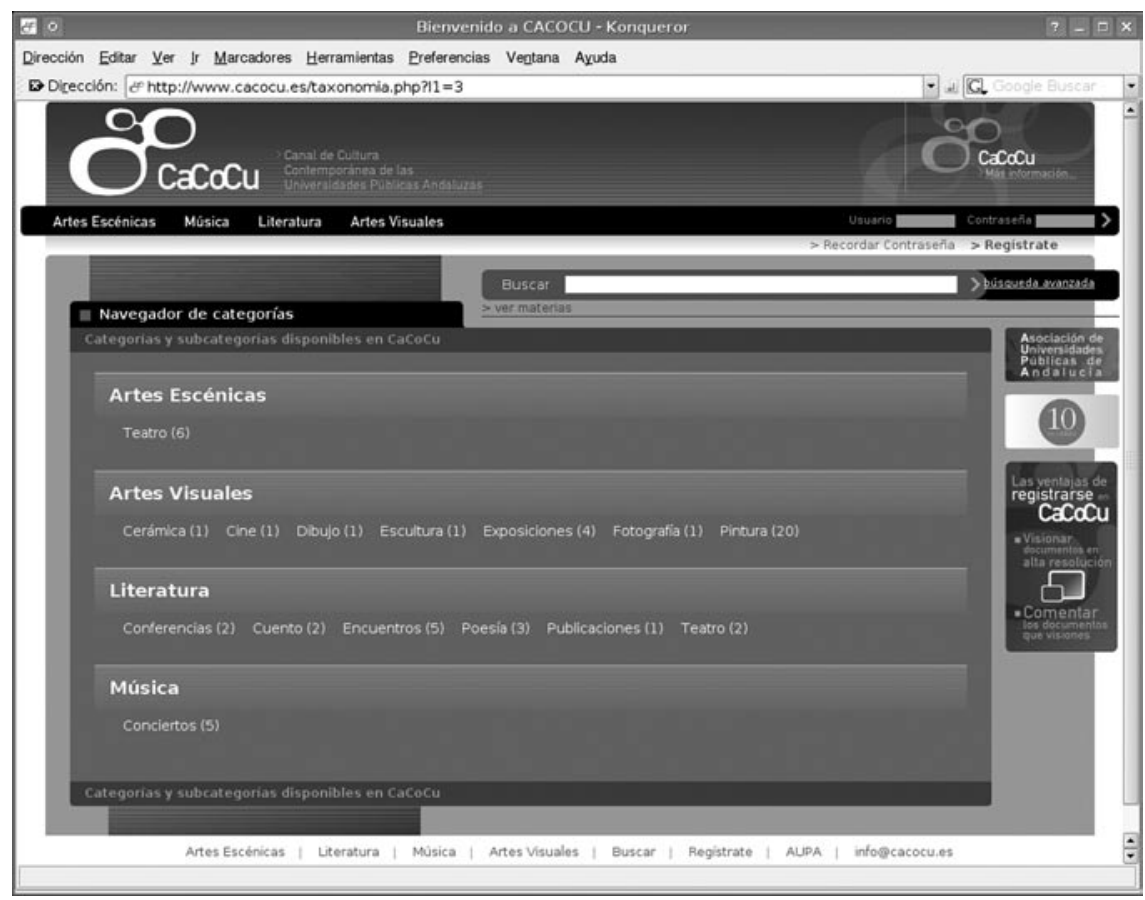

Figura 5. Navegación a través de la taxonomía

\section{¿Recibes ya E P I en casa? \\ Por sólo 75 euros \\ $+$ \\ $4 \%$ IVA}

puedes tener todos los meses tu copia particular y leerla cómodamente cuando quieras. 


\section{EPI en MetaPress}

Los suscriptores tienen acceso online (pdf y html) a todo el período 2000-2007 en la web:

http://elprofesionaldelainformacion.metapress.com

MetaPress (empresa situada Alabama, EUA), del grupo Ebsco, es el mayor distribuidor de revistas-e (con clientes como Springer, Taylor \& Francis, IOS Press, etc.) y dispone de complejos dispositivos de seguridad que garantizan la conservación de EPI y un acceso perpetuo 24/7.

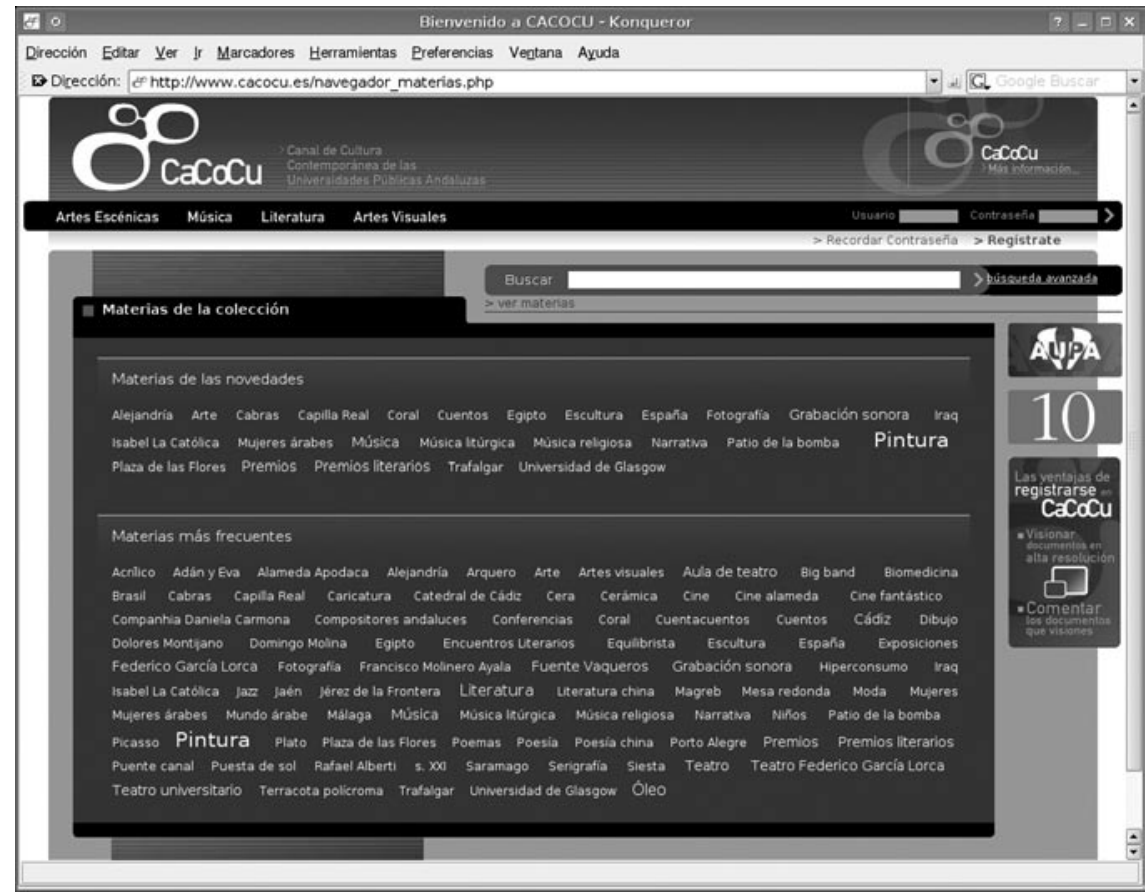

Figura 6. Navegación a través de "Ver materias"

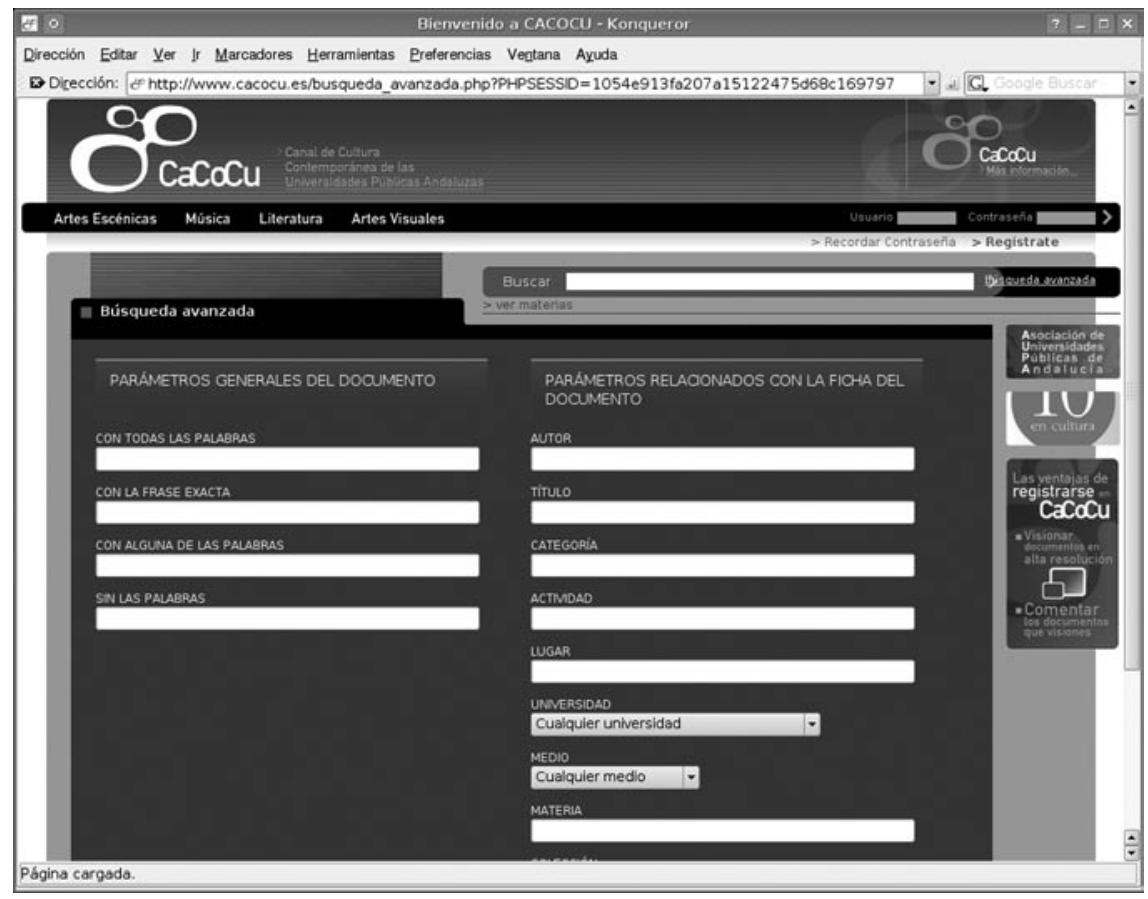

Figura 7. Buscador avanzado

\section{Documentos de texto}

De los libros, catálogos, etc., se presenta la portada y la contraportada en el visor, y se puede descargar el contenido completo en formato pdf.

\section{Otros servicios}

- Buscadores.

- Comentarios.

- Registro de usuarios.

- Sindicación.

- Estadísticas de acceso.

- Administración de contenidos.

\section{Acceso a los contenidos del portal}

CaCoCu brinda a los usuarios cuatro puertas de entrada. Así, dependiendo del manejo de la web y de los lenguajes de recuperación que posea cada uno, accederá de una manera u otra (ver la figura 4).

\subsection{Taxonomía}

Navegación por una clasificación previamente establecida. En la figura 5 se observa que debajo de cada categoría (nivel 1) cuelgan las diferentes subcategorías (nivel 2) junto a su peso entre paréntesis, o lo que es lo mismo, el número de documentos que contienen ese término como elemento de clasificación o descriptor.

\subsection{Materias}

Figura 6. El usuario localiza los documentos consultando dos listados de materias que se generan 


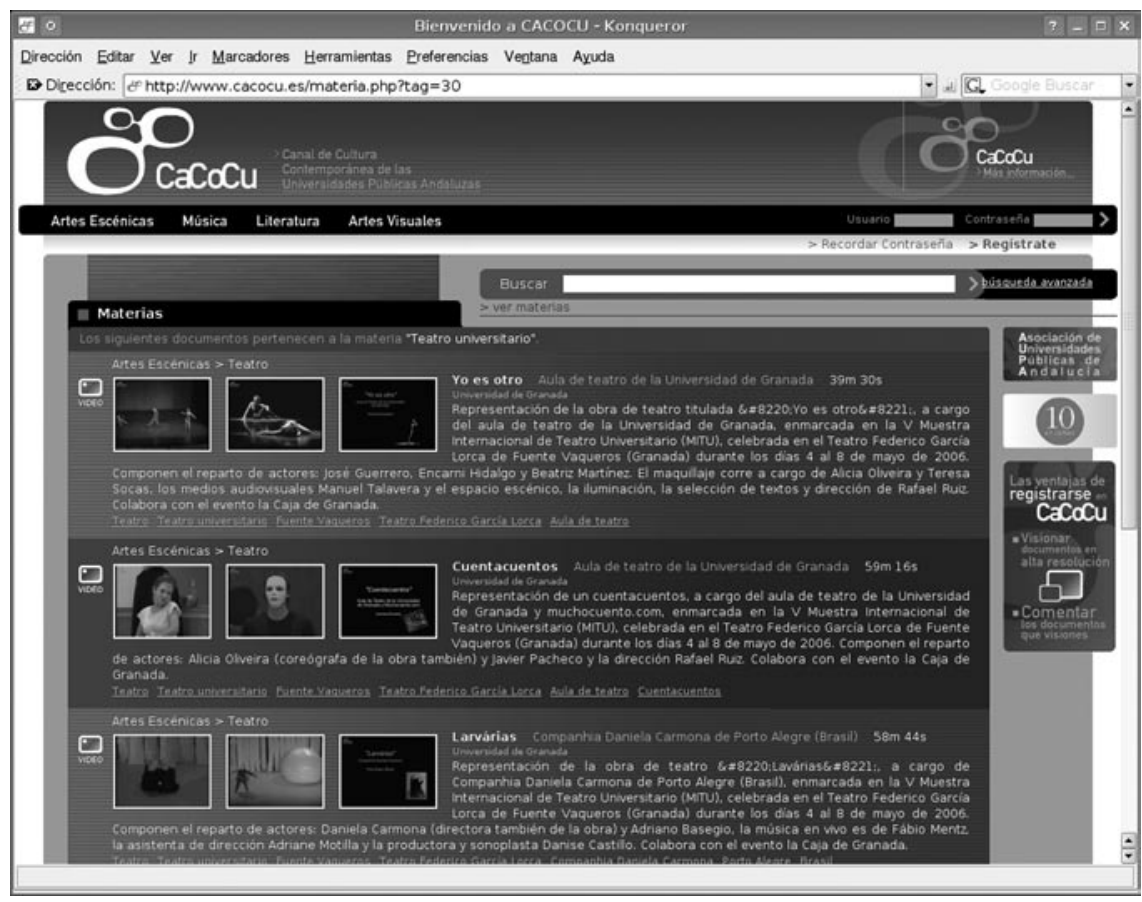

Figura 8. Formato de devolución de resultados de consulta

de forma automática: por novedad (adquisiciones recientes) y por popularidad (las que se asignan con mayor frecuencia a los documentos). En cualquier caso sus pesos se indican visualmente mediante el tamaño de letra: cuanto mayor sea la fuente con que aparece escrito su nombre, mayor es el número de documentos disponibles. El manejo de esta puerta de entrada es sumamente intuitivo y supone una interesante característica de tipo web 2.0 .

\subsection{Buscador}

Buscador clásico.

\subsection{Búsqueda avanzada}

Figura 7. Booleana por varios campos, frase exacta, etc. Ver ejemplo de presentación de resultados en la figura 8 .

\section{Trabajo futuro $y$ conclusiones}

Se ha implementado un portal web cultural que ofrece contenidos multimedia: grabaciones de vídeo y audio, galerías de imágenes y textos, de las actividades culturales organizadas por las universidades públicas de Andalucía (obras de teatro, encuentros literarios, conferencias, ediciones musicales, novelas, poesía, etc). Como trabajo futuro, además de seguir añadiendo los nuevos materiales que generen las universidades, se pretende abordar otras tareas:

- Permitir la difusión de vídeo en directo.

- Ampliar la funcionalidad del portal: activación de alertas, implementación de unos foros de discusión, posibilidad de que los usuarios suban sus propias creaciones (módulo de Net.Art), etc.

- Recuperar el patrimonio cultural más antiguo, convirtiéndolo en un formato digital y haciendo más accesible la memoria histórica de las universidades andaluzas.

\section{Referencias bibliográficas}

1. O'Reilly, Tim. What is web 2.0: design patter ns and business models for the next generation of software. Consultado en: 19-01-07.

http://www.oreillynet.com/pub/a/oreilly/tim/ news/2005/09/30/what-is-web-20.html

2. DiarioTi: Diario tecnologías de la información. Consultado en: 19-01-07.

http://diarioti.com/gate/n.php?id=12089

Noticias Google en español. Consultado en: 1901-07.

http://google.dirson.com
3. Estalella, Adolfo. "El vídeo se cuela con fuerza en internet". En: Cinco días, 2006, diciembre, pp. 14-29.

4. Marín Amatller, Antoni. "Vídeo digital en internet". En: Mosaic: tecnologías y comunicación multimedia, 2005, n. 41

5. AUPA (Asociación de Universidades Públicas de Andalucía). Las diez universidades que la integran son: Almería, Cádiz, Córdoba, Granada, Huelva, Internacional de Andalucía, Jaén, Málaga, Pablo de Olavide y Sevilla. Consultado en: 18-01-07.

http://www.aupa.info

6. World Wide Web Consortium. Consultado en 19-01-07.

http://www.w3c.org

7. PHP: Hipertext PreProcessor. Consultado en: 19-01-07.

http://www.php.net

8. MySQL AB: the world's most popular open source database. Consultado en: 19-01-07. http://www.mysql.com

9. The Apache Software Foundation. Consultado en: 19-01-07.

http://www.apache.org

10. Windows media services 9 Series. Consultado en: 19-01-07.

http://www.microsoft.com/windows/windowsmedialforpros/server/server.aspx

11. Introducción a la accesibilidad web. Consultado en: 19-01-07.

http://www.w3c.es/Traducciones/es/WAI/intro/ accessibility

12. RSS Advisory Board. Consultado en: 19-01-07. http://www.rssboard.org

José-Luis Bernier, Departamento de Arquitectura y Tecnología de Computadores, Universidad de Granada jbernier@atc.ugr.es

David Gómez-Domínguez, Biblioteca Universitaria, Hospital Real, Universidad de Granada.

dgomez@ugr.es

Gerardo Fernández-Rodríguez, Departamento de Arquitectura y Tecnología de Computadores, Universidad de Granada.

gerfer@correo.ugr.es

Mario Barchéin, Departamento de Arquitectura y Tecnología de Computadores, Universidad de Granada. mario@terragiro.es

Gregorio Pérez, Dixi Estudio Grafismo, Granada.

gregorio@dixi-e.com 